\title{
Effects of Cold Rolling Deformation on Microstructure and Damping Capacity of a Fe-Mn-Cr-Co-Si Alloy
}

\author{
Lei Meng ${ }^{a}$, Xiaoming Zhang ${ }^{a}$ * \\ ${ }^{a}$ State Key Laboratory of Rolling and Automation, Northeastern University, Shenyang 110819, \\ $P R$, China
}

Received: December 13, 2018; Revised: March 02, 2019; Accepted: April 04, 2019

\begin{abstract}
The microstructure evolution of Fe-19Mn-8Cr-1Co-0.2Si (wt.\%) alloy and Fe-19Mn (wt.\%) alloy during cold rolling and its effect on the damping capacity of the two alloys were investigated. It was shown that the damping capacity of the two alloys was enhanced significantly owing to the deformationinduced $\varepsilon$-martensite and stacking faults. The Fe- $19 \mathrm{Mn}-8 \mathrm{Cr}-1 \mathrm{Co}-0.2 \mathrm{Si}$ alloy exhibited an accelerated phase transformation from $\gamma$-austenite to $\varepsilon$-martensite due to a higher content of retained $\gamma$-austenite and larger grain sizes compared with the Fe-19Mn alloy, resulting in a higher maximal increment of damping capacity in this alloy caused by deformation. It was observed that no twinned $\varepsilon$-martensite was generated in the $\mathrm{Fe}-19 \mathrm{Mn}-8 \mathrm{Cr}-1 \mathrm{Co}-0.2 \mathrm{Si}$ alloy during cold rolling, resulting in a remarkable increase in the volume fraction of $\alpha^{\prime}$-martensite owing to no impediment to $\varepsilon \rightarrow \alpha^{\prime}$ transformation, hence the deterioration of damping capacity was slow because the $\alpha^{\prime}$-martensite weakened the pinning effect of dislocations on damping sources. In addition, new damping sources were provided due to the occurance of $\gamma$-austenite twinning in the Fe-19Mn-8Cr-1Co-0.2Si alloy.
\end{abstract}

Keywords: $\mathrm{Fe}$-Mn based damping alloy, martensite transformation, cold rolling, damping capacity.

\section{Introduction}

Metallic materials with a high damping capacity, such as $\mathrm{Mn}-\mathrm{Cu}$ alloys, Ni-Ti alloys, $\mathrm{Zn}$-Al alloys, Mg-based alloys and Fe-based alloys, are widely employed in automobiles, instrumentation, industrial facilities and other applications due to the significant effect on noise and vibration reduction ${ }^{1-3}$. Recently, Fe-Mn based alloys become a research hotspot among damping alloys because they possess high damping capacity, excellent mechanical properties and low cost compared with non-ferrous damping alloys ${ }^{4,5}$.

It is well known that four damping sources ${ }^{6,7}$, including stacking fault (SF), boundaries in the $\gamma$-austenite and $\varepsilon$-martensite, $\varepsilon$-martensite $/ \gamma$-austenite interfaces and $\varepsilon$-martensitic variant boundaries, are presented in Fe-Mn alloys with $\gamma$-austenite (fcc) to $\varepsilon$-martensite (hcp) phase transformation. Boundaries mentioned above are essentially formed by slipping of Shockley partial dislocations and the density of Shockley partial dislocations depends on the stacking fault energy (SFE) of the alloy ${ }^{8-10}$. The damping mechanism was described by the G-L dislocation motion model proposed by Granato and Lücke ${ }^{1,11}$, indicating that the high damping capacity is originated from the hysteretic movement of partial dislocations under cyclic stress. According to the model, increasing the number of damping source interfaces is one of the most effective ways to improve the damping capacity of Fe-Mn alloys, moreover, the number can be significantly increased by deformation induced $\gamma$-austenitic to $\varepsilon$-martensitic phase transformation $^{12-14}$.
Jun et al. ${ }^{12}$ observed that the damping capacity of Fe-23Mn (wt.\%) alloy increased with the deformation during cold rolling, exhibiting a maximum value at a strain of 5\%, and then it decreased rapidly with a larger amount of deformation. The fraction of $\varepsilon$-martensite increased during cold rolling in conjunction with the transformation-induced plasticity (TRIP) effect, resulting in an increase of damping sources. Beyond $5 \%$ deformation, the occurrence of $\varepsilon$-martensite to $\alpha$-martensite (bcc or bct) transformation and the increase of the non-movable dislocation density led to a quick deterioration in the damping capacity. Besides, Huang et al.'s research ${ }^{13}$ indicated that the stress-induced stacking faults formed in the pre-deformation could increase the damping capacity of Fe-Mn alloys. Many studies have revealed that tensile or cold rolling deformation can improve the damping capacity of Fe-Mn alloys. However, there are few works which illustrate the differences between Fe-Mn-Cr based alloys with relatively high SFE and Fe-Mn alloys with low SFE in the microstructure evolution and damping capacity during plastic deformation.

In the present work, a $\mathrm{Fe}-19 \mathrm{Mn}-8 \mathrm{Cr}-1 \mathrm{Co}-0.2 \mathrm{Si}$ (wt.\%) alloy and the reference binary Fe-19Mn (wt.\%) alloy was prepared. The addition of $\mathrm{Cr}$ had a positive influence on the corrosion resistance and toughness but led to an increase in the SFE of Fe-Mn alloys, resulting in a low $\varepsilon$-martensitic transformation temperature ${ }^{15}$. Whereas, the small addition of $\mathrm{Co}$ and Si could appropriately reduce the SFE of Fe-Mn alloys, ensuring a sufficiently high damping capacity by increasing 
the fraction of $\varepsilon$-martensite ${ }^{16}$. This study is to investigate the microstructural evolution during plastic deformation and its effect on the damping capacity of these two alloys.

\section{Experimental Procedure}

The two alloys were melted by a high-frequency vacuum induction furnace in a protective atmosphere of argon and cast into copper molds. Industrial pure iron, electrolytic manganese, metallic chromium, cobalt and crystalline silicon were used as raw materials. The chemical compositions of the two alloys are listed in Table 1. The ingots were reheated and homogenized at $1200{ }^{\circ} \mathrm{C}$ for $6 \mathrm{~h}$ in an electrical resistance furnace. Then ingots were hot-rolled into $3 \mathrm{~mm}$ thickness plates and then cooled to room temperature in air. Hot-rolled plates were solution treated at $1050{ }^{\circ} \mathrm{C}$ for $0.5 \mathrm{~h}$, followed by cooling to room temperature in water. These plates were further cold-rolled in order to achieve $5 \%-20 \%$ reduction in thickness.

Samples were prepared from the solution-treated plates for the determination of phase transformation temperature. The dimensions are $10 \mathrm{~mm}$ in length, $4 \mathrm{~mm}$ in width and 2 $\mathrm{mm}$ in thickness and both ends in the length direction are guaranteed to be parallel. Finally, dilatometric curves were measured using a quenching and deformation dilatometer (DIL 805A/D).

For microstructure observation, X-ray diffraction (XRD), transmission electron microscopy (TEM) and electron back-scattered diffraction (EBSD) samples were cut from the solution-treated plates and cold-rolled plates, respectively. The surfaces of XRD and EBSD samples were mechanically polished and then electropolished in a solution of $12.5 \% \mathrm{HClO}_{4}$ and $87.5 \% \mathrm{C}_{2} \mathrm{H}_{5} \mathrm{OH}$ to eliminate surface stress layer. The XRD measurement was conducted by a Smart Lab 9kW X-ray diffractometer using $\mathrm{Cu} K_{\alpha}$ radiation. During the scan of samples, the scanning range is $40^{\circ}$ to $100^{\circ}$ and the step size is $4 \% \mathrm{~min}$. The EBSD scans were performed on a field-emission scanning electron microscope (Zeiss Ultra 55) equipped with an electron back-scattered diffraction attachment. The scanning step size of EBSD measurement is $0.1 \mu \mathrm{m}$ and the raw data were processed by HKL CHANNEL 5 software. The TEM specimens were ground to $\sim 45 \mu \mathrm{m}$ and then thinned by electropolishing with a twin-jet electropolisher (Struers TenuPol-5) at $\sim 32 \mathrm{~V}$ and $\sim-25^{\circ} \mathrm{C}$ using electrolyte solution consisting of $10 \% \mathrm{HClO}_{4}$ and $90 \% \mathrm{C}_{2} \mathrm{H}_{5} \mathrm{OH}$. The TEM used was a field-emission TEM (FEI Tecnai $\mathrm{G}^{2}$ F20).
The damping capacity was evaluated by a single cantilever beam method on a dynamic mechanical analyzer (DMA-Q800). Cantilever beam samples with dimensions of $35 \mathrm{~mm}$ in length, $5 \mathrm{~mm}$ in width and 0.8 in thickness were subjected to bend and then decayed freely in order to obtain the stress-strain curves. The testing temperature was $20^{\circ} \mathrm{C}$, the frequency was $1 \mathrm{~Hz}$ and the wide range of strain amplitude was $1 \times 10^{-4}$ to $1 \times 10^{-3}$. Moreover, the tangent of the phase angle of strain hysteresis stress $(\tan \varphi)$ was used to indicate the damping capacity.

\section{Results and Discussion}

\subsection{Microstructure}

In order to obtain the phase transformation temperature and indirectly compare the SFE of the two alloys used in the present work, dilatometric curves of the $\gamma \leftrightarrow \varepsilon$ phase transformation was measured with a thermal cycle from room temperature to $1050{ }^{\circ} \mathrm{C}$. The results are shown in Fig. 1 . According to these curves, the start and stop temperatures of austenite transformation $\left(\mathrm{A}_{\mathrm{s}}\right.$ and $\left.\mathrm{A}_{\mathrm{f}}\right)$ and the start temperature of $\varepsilon$-martensitic transformation $\left(\mathrm{M}_{\mathrm{s}}\right)$ can be determined, respectively. It is obvious that the $\mathrm{M}_{\mathrm{s}}$ temperature of the Fe-19Mn alloy $\left(\sim 155^{\circ} \mathrm{C}\right)$ is significantly higher than that of Fe-19Mn-8Cr-1Co-0.2Si alloy $\left(\sim 104^{\circ} \mathrm{C}\right)$, which indicates that $\mathrm{Cr}$ is a strong austenite stabilizer and the SFE of the Fe-19Mn-8Cr-1Co-0.2Si alloy is higher.

The EBSD crystallographic analysis results for the Fe-19Mn and Fe-19Mn-8Cr-1Co-0.2Si alloys after solution treatment are presented in Fig. 2. The highly similar microstructures of the two alloys consisted of two phases, which are the pre-existing thermal-induced $\varepsilon$-martensite with a hexagonal close-packed crystal structure formed on cooling and the pre-existing $\gamma$-austenite with a face-centered cubic crystal structure. Fig. 3 exhibits the XRD profiles of the two alloys after solution treatment. The diffraction peaks of $\gamma$-austenite and $\varepsilon$-martensite were confirmed and labelled in this figure. Due to the peak overlaps between (113) and $(11 \overline{2} 2)_{\varepsilon}$ at $91.2^{\circ}$ and $(022)_{\gamma}$ and $(11 \overline{2} 0)_{\varepsilon}$ at $74.9^{\circ 17,18}$, the method used by Chen et al. ${ }^{10}$ was also used here to estimate the volume fractions of the $\gamma$-austenite and $\varepsilon$-martensite. For the Fe-19Mn alloy, the volume fractions of $\gamma$-austenite and $\varepsilon$-martensite were $16.6 \%$ and $83.4 \%$, respectively. However, for the Fe-19Mn-8Cr-1Co-0.2Si alloy, the volume fractions of $\gamma$-austenite and $\varepsilon$-martensite were estimated to be $27.2 \%$ and $72.0 \%$, respectively. This result indicates that

Table 1. Chemical compositions of the two alloys, wt.\%.

\begin{tabular}{lcccccccc}
\hline Alloy & $\mathrm{Mn}$ & $\mathrm{C}$ & $\mathrm{Cr}$ & $\mathrm{Co}$ & $\mathrm{Si}$ & $\mathrm{P}$ & $\mathrm{S}$ & $\mathrm{Fe}$ \\
\hline Fe-19Mn-8Cr-1Co-0.2Si & 19.30 & 0.016 & 8.01 & 0.96 & 0.016 & 0.004 & 0.005 & balance \\
Fe-19Mn & 19.01 & 0.010 & - & - & - & 0.005 & 0.003 & balance \\
\hline
\end{tabular}




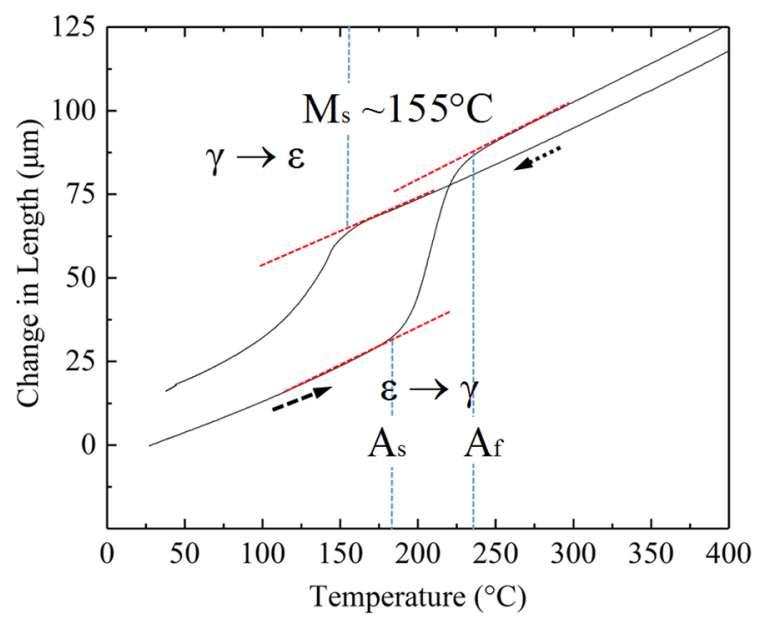

(a)

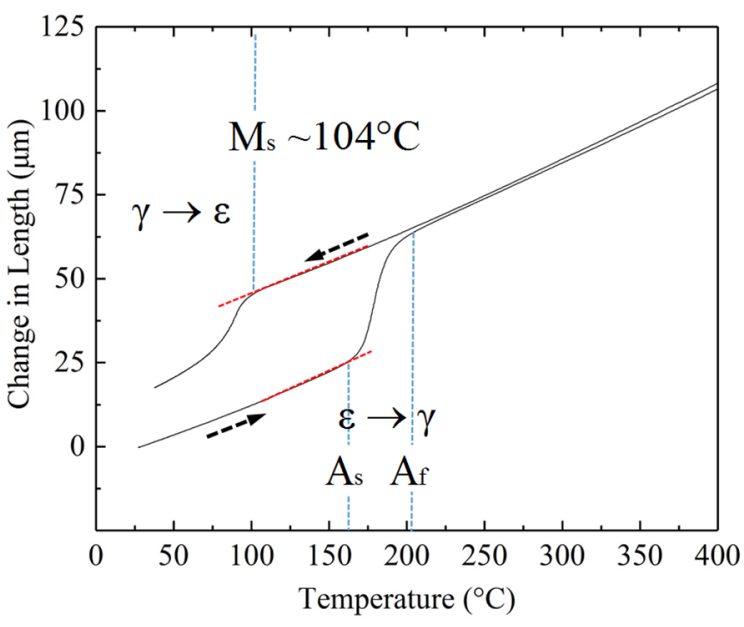

(b)

Figure 1. Dilatometric curves: (a) the Fe-19Mn alloy; (b) the Fe-19Mn-8Cr-1Co-0.2Si alloy.

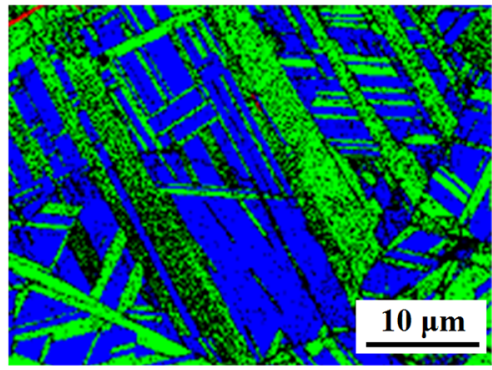

(a)

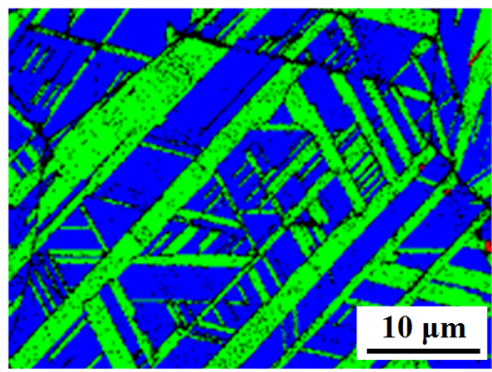

(d)

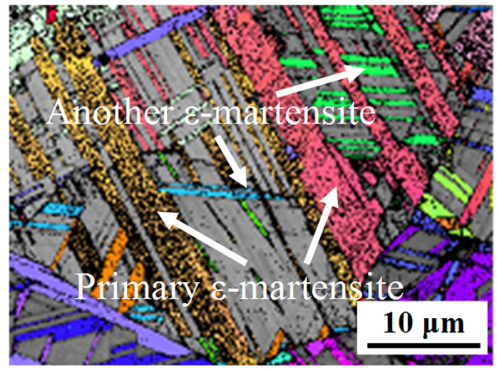

(b)

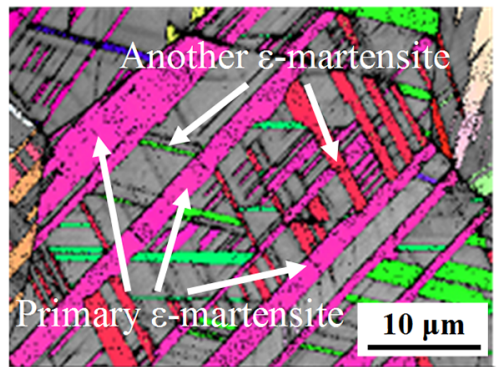

(e)

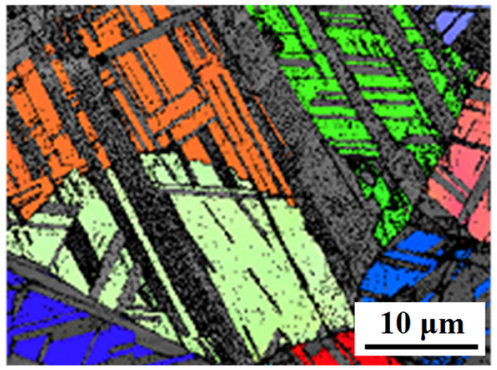

(c)

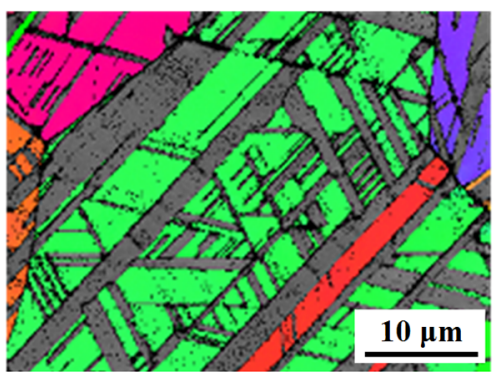

(f)

$\gamma$-austenite

$\varepsilon$-martensite

Figure 2. EBSD analyses on (a), (b) and (c) the Fe-19Mn alloy and (d), (e) and (f) the Fe-19Mn-8Cr-1Co-0.2Si alloy after solution treatment: (a) and (d) the phase maps; (b) and (e) the inverse pole figure maps of $\varepsilon$-martensite; (c) and (f) the inverse pole figure maps of austenite.

the volume fraction of $\gamma$-austenite is higher in the high SFE alloy owing to the large degree of undercooling relative to the $\mathrm{M}_{\mathrm{s}}$. As observed in Fig. 2, the prior austenite grain is always divided by multiple-variant $\varepsilon$-martensitic plates. Moreover, the relatively thicker primary $\varepsilon$-martensitic plate usually nucleates at the prior $\gamma$-austenite grain boundaries and grows across the whole prior $\gamma$-austenite grain, as shown in Figs. $2 \mathrm{~b}$ and $2 \mathrm{e}$. In addition, there are many thinner $\varepsilon$-martensitic plates (another $\varepsilon$-martensite) with different crystallographic orientations from the primary $\varepsilon$-martensitic plates. These plates spear to be formed at the pre-existing $\gamma$-austenite/ primary $\varepsilon$-martensite interfaces and grow starting at $\gamma / \varepsilon$ interface and stopping at the other $\gamma / \varepsilon$ interface. The growth of other variant $\varepsilon$-martensitic plates is hence impeded by the pre-existing primary $\varepsilon$-martensitic plates. 


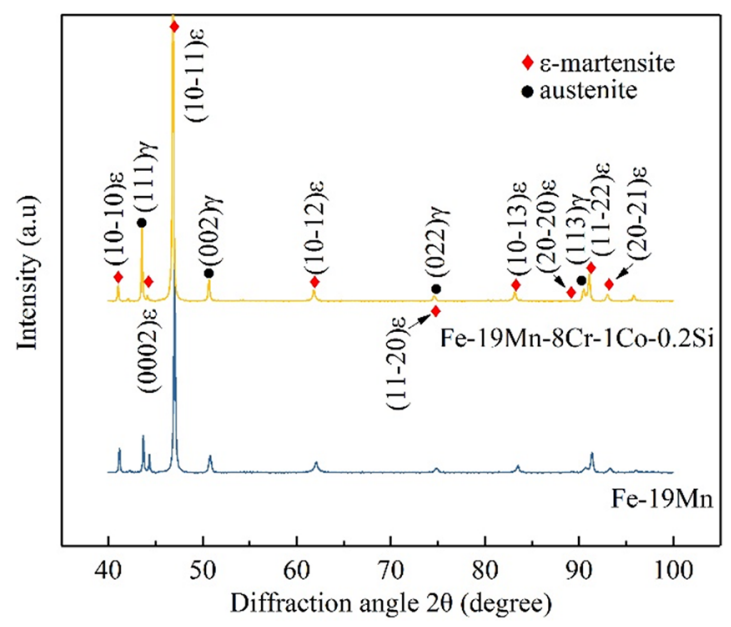

Figure 3. XRD patterns of the Fe-19Mn and Fe-19Mn-8Cr-1Co$0.2 \mathrm{Si}$ alloys after solution treatment.

The TEM micrographs of the Fe-19Mn and Fe-19Mn$8 \mathrm{Cr}-1 \mathrm{Co}-0.2 \mathrm{Si}$ alloys after solution treatment at $1050{ }^{\circ} \mathrm{C}$ for $0.5 \mathrm{~h}$ are shown in Fig. 4. The bright-field images, as shown in Figs. 4a and 4c, reveal that the Fe-19Mn alloy possesses massive $\varepsilon$-martensitic plates with a straight boundary and numerous stacking faults in $\gamma$-austenite and $\varepsilon$-martensite on cooling. Besides, numerous thin $\varepsilon$-martensitic layers formed in this alloy. These are only several nnanometers thick, whereas the large plates have a large thickness of up to $100 \mathrm{~nm}$. Fig. $4 \mathrm{~d}$ is the corresponding dark-field image of $\varepsilon$-martensite shown in Fig. $4 \mathrm{c}$, showing that these thermally induced $\varepsilon$-martensitic plates do not have a complete monolithic structure, but consist of numerous thin $\varepsilon$-martensitic layers, which are interspersed with residual $\gamma$-austenite matrix structure. This is in good agreement with the report of Yamanaka et al. ${ }^{19}$ showing that the thermally induced $\varepsilon$-martensitic plates are formed through successive nucleation and growth of thin $\varepsilon$-martensitic layers. The bright-field TEM image of the Fe-19Mn-8Cr-1Co-0.2Si alloy is shown in Fig. 4b, existing an analogical TEM micrograph with the Fe-19Mn alloy. Moreover, the selected area electron diffraction pattern (SAEDP) shown in Fig. 4b presents the orientation relationship between $\gamma$-austenite and $\varepsilon$-martensite is $[011]_{\gamma} / /[2 \Pi 0]_{\varepsilon}$ and $(11 \mathrm{~T})_{\gamma} / /(0002)_{\varepsilon}$, obeying the Shoji-Nishiyama (S-N) type ${ }^{10}$.

Fig.5 exhibits XRD profiles of the two alloys after cold rolling. The diffraction peaks of $\alpha^{\prime}$-martensite with a body-centered cubic or tetragonal crystallographic structure were observed in both alloys, revealing that deformation-induced $\alpha^{\prime}$-martensitic phase transformation occurred during cold rolling. Owing to the additional peak overlap between $(0002)_{\varepsilon}$ and $(011)_{\alpha^{\prime}}$ at $44.5^{\circ 17,18}$, the above method was used to estimate the volume fractions of the phases, and the results are listed in Table 2.

The results show that deformation-induced $\gamma \rightarrow \varepsilon$ and $\varepsilon \rightarrow \alpha^{\prime}$ phase transformations occurred in the two alloys during cold rolling ${ }^{7,12}$. With the increase of the amount of deformation, the volume fraction of $\gamma$-austenite decreases in both alloys and the volume fraction of $\varepsilon$-martensite increases until reaching a critical value, then begins to saturate or to fall owing to the increase of the fraction of the $\alpha^{\prime}$-martensite.

According to the fractional change of $\varepsilon$-martensite shown in table 2 , at the same deformation, the transformation rate of pre-existing $\gamma$-austenite to deformation-induced $\varepsilon$-martensite in the Fe-19Mn-8Cr-1Co-0.2Si alloy is higher than in the $\mathrm{Fe}-19 \mathrm{Mn}$ alloy. The "constraining effect" mentioned by Seol et al. ${ }^{17}$ revealed that the phase transformation of $\gamma \rightarrow \varepsilon$ during plastic deformation was mainly controlled by the mechanical stabilization of $\gamma$-austenite phase. In other words, in the alloy possessing the $\gamma$-austenite with a high fraction and a large grain size, the $\gamma \rightarrow \varepsilon$ phase transformation is easier due to the mechanical stabilization of austenite deteriorated with increasing deformation. The average grain sizes of the two alloys were determined by EBSD. The result shows that average grain sizes of $\gamma$-austenite in the Fe-19Mn- $8 \mathrm{Cr}$ 1Co-0.2Si and Fe-19Mn alloys were $\sim 2.9 \mu \mathrm{m}$ and $\sim 2.4$ $\mu \mathrm{m}$, respectively, indicating that the average grain size of former is larger. Therefore, the Fe- $19 \mathrm{Mn}-8 \mathrm{Cr}-1 \mathrm{Co}-0.2 \mathrm{Si}$ alloy exhibits an accelerated transformation of $\gamma \rightarrow \varepsilon$ in the plastic deformation due to the larger grain size and high content of austenite.

There is an unusual phenomenon in Table 2. The transformation rate of deformation-induced $\varepsilon \rightarrow \alpha^{\prime}$ in the $\mathrm{Fe}-19 \mathrm{Mn}$ alloy is slower than in the Fe-19Mn-8Cr-1Co$0.2 \mathrm{Si}$ alloy at the same deformation, although the content of $\varepsilon$-martensite is higher in the $\mathrm{Fe}-19 \mathrm{Mn}$ alloy. It indicates that $\varepsilon$-martensite in the $\mathrm{Fe}-19 \mathrm{Mn}$ alloy may have other means to relax other than $\varepsilon \rightarrow \alpha^{\prime}$ phase transformation. This will be discussed in detail later.

Fig. 6 shows the EBSD phase and inverse pole figure (IPF) maps of the two alloys after cold rolling and clearly presents the distribution and morphology of deformationinduced $\varepsilon$ - and $\alpha^{\prime}$-martensite. To relax the stress concentration, the deformation-induced $\varepsilon$ to $\alpha^{\prime}$ phase transformation occurs in the two alloys. Most deformation-induced $\alpha^{\prime}$-martensite is formed within a single $\varepsilon$-martensitic plate and divided the $\varepsilon$-martensitic plate into several small sections as shown in Fig. 6d, and only few $\alpha^{\prime}$-martensite is observed at the intersection of several $\varepsilon$-martensite bands, as indicated by the mark $\mathrm{C}$. In addition, the extremely thin twinned $\varepsilon$-martensitic phases, as indicated by arrows in Fig. 6b, are detected in the Fe-19Mn alloy at 5\% deformation. Seol et al. ${ }^{17}$ suggested that the occurrence of $\varepsilon$-martensitic twins can relieve the stress concentration in the pre-existing $\varepsilon$-martensite and thereby postpones the deformation-induced $\varepsilon$ to $\alpha^{\prime}$ phase transformation. However, $\varepsilon$-martensitic twins are not found in the Fe-19Mn-8Cr-1Co-0.2Si alloy, meaning that the transformation velocity of $\varepsilon$ to $\alpha^{\prime}$ is faster and the fraction of $\alpha^{\prime}$-martensite is therefore higher in this alloy at the same deformation, as shown in Figs. 6c, 6f, $6 \mathrm{i}$ and 61. 


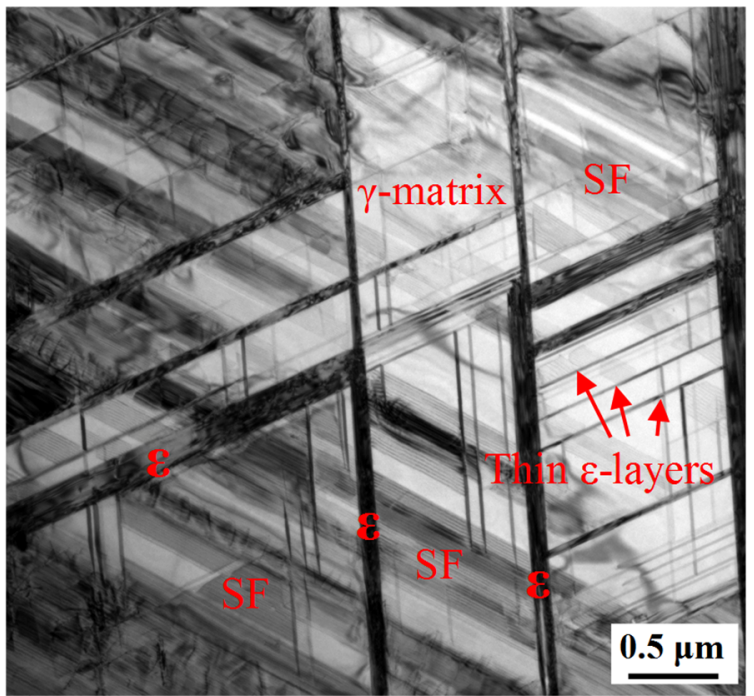

(a)

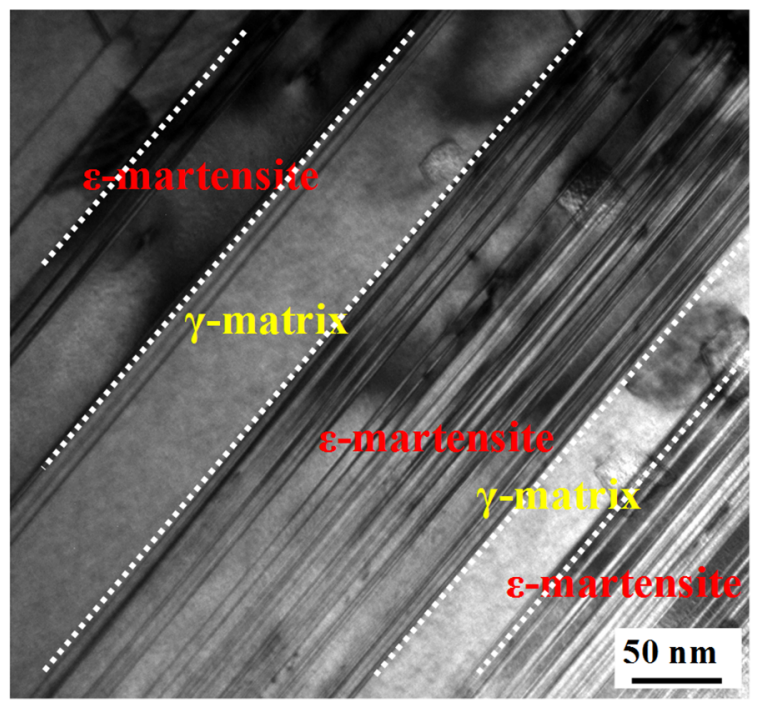

(c)

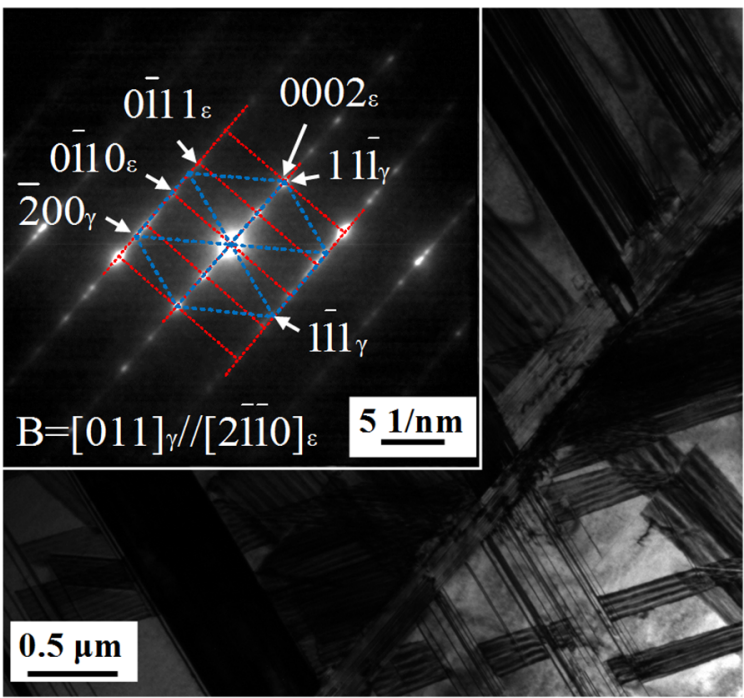

(b)

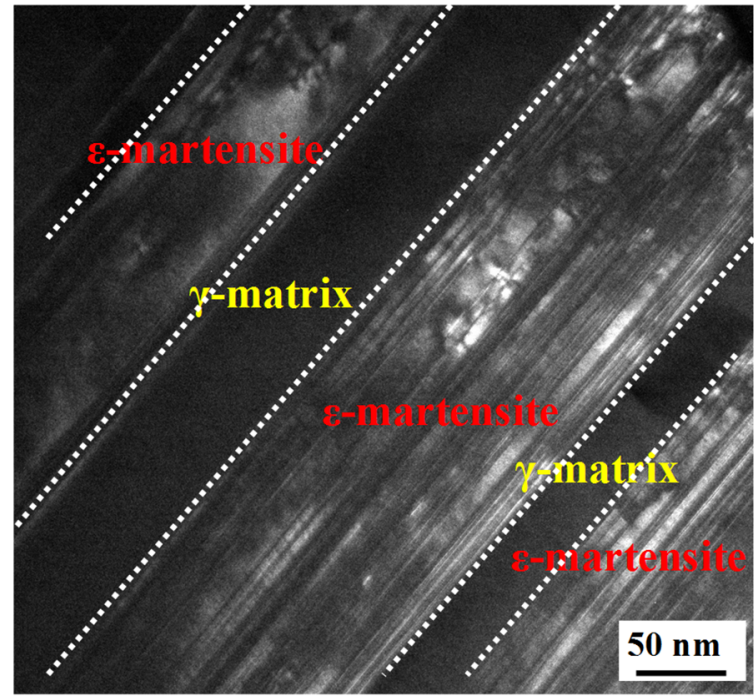

(d)

Figure 4. TEM micrographs of (a), (c) and (d) the Fe-19Mn alloy and (b) the Fe-19Mn-8Cr-1Co-0.2Si alloy after solution treatment: (a) the bright-field image of Fe-19Mn, showing $\gamma$-austenite matrix, $\varepsilon$-martensite, thin $\varepsilon$-martensite layers and stacking faults; (b) the bright-field image with inset of SAEDP; (c) the brightfield image and (d) the corresponding dark-field image, showing the internal structure of $\varepsilon$-martensite laths.

Seol and co-workers ${ }^{17}$ reported that the $\alpha^{\prime}$-martensite was generated from the pre-existing thermal-induced $\varepsilon$-martensite observed by EBSD monitoring in suit and the deformation-induced $\varepsilon$-martensite formed by $\gamma$ to $\varepsilon$ phase transformation could not further transform, hence the deformation-induced $\varepsilon$-martensite have no any contribution to $\varepsilon$ to $\alpha$ ' phase transformation. In other words, transformations occurred during whole deformation process are pre-existing $\gamma$ to deformation-induced $\varepsilon$ and thermal-induced $\varepsilon$ to deformation-induced $\alpha^{\prime}$. In Figs. 6e and 6k, mark A represents the pre-existing thermal-induced $\varepsilon$-martensite plates within which many $\alpha^{\prime}$-martensite layers formed, as indicated by white arrows in Figs. 6d, 6f, 6j and 61, whereas mark B represents the deformation-induced $\varepsilon$-martensite in which no $\alpha^{\prime}$-martensite formed in the plates and the phase boundaries of the $\varepsilon$-martensite are no longer straight.

The deformation-induced $\varepsilon$-martensite nucleates at the thermal-induced $\varepsilon / \gamma$ interfaces and grows into the $\gamma$ phase to fill the gap between the thermal-induced $\varepsilon$-martensitic plates end to encounter other thermal-induced $\varepsilon / \gamma$ interfaces. The 


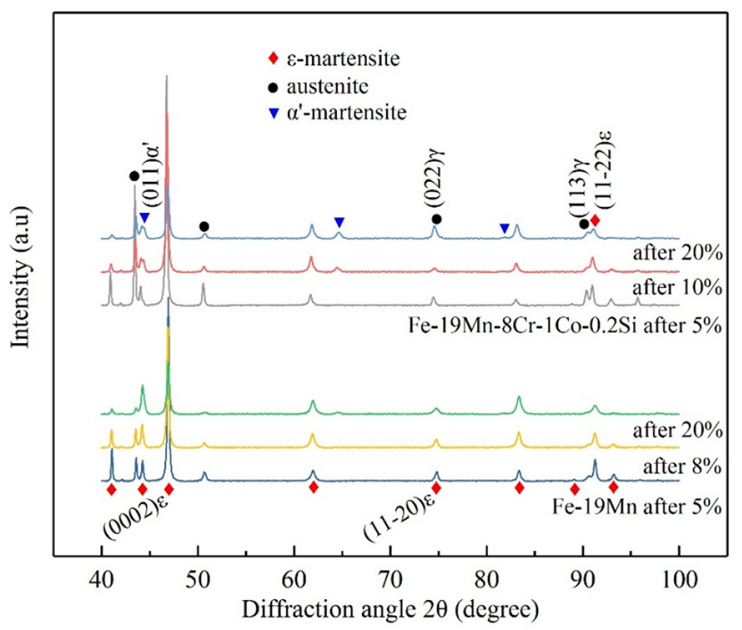

Figure 5. XRD patterns of the Fe-19Mn and Fe-19Mn- $8 \mathrm{Cr}-1 \mathrm{Co}-$ $0.2 \mathrm{Si}$ alloys after cold rolling.

orientation of deformation-induced $\varepsilon$-martensite is mainly controlled by cold rolling direction. Customarily, all Shockley partial dislocations of $<211>$ glide directions on $\{111\}$ habit planes are responsible for the $\gamma$ to $\varepsilon$ transformation, however, the preferred glide direction occurs and it is activated to complete the transformation during cold rolling.

Fig. 7 provides the TEM micrographs and SAEDPs of the Fe-19Mn-8Cr-1Co-0.2Si alloy after $20 \%$ cold-rolled deformation, therein Figs. 7e, $7 \mathrm{f}$ and $7 \mathrm{~g}$ represent the SAEDPs corresponding with region $\mathrm{A}, \mathrm{B}$ and $\mathrm{C}$, respectively. As shown in Fig. 7e, the SAEDP indicates that the orientation relationship between $\gamma$-austenite and $\varepsilon$-martensite still obeys the S-N type. The $\varepsilon$-martensite is closely intertwined with the $\gamma$-austenite after deformation and high-density dislocations are observed in the bright-field image shown in Fig. 7a. In addition, the SAEDP shown in Fig. 7 f reveals the occurrence of the $\gamma$-austenite mechanical twins. But as previously discussions, mechanical twins are inexistent in the as-solution treated Fe-19Mn-8Cr-1Co-0.2Si alloy (Fig. 4b). Significantly, Chen et al. ${ }^{20}$ proposed that no twinned $\gamma$-austenite was occurred in the binary $\mathrm{Fe}-15 \mathrm{Mn}$ damping alloy after deformation, however, $\varepsilon$-martensite twins were existed in the deformed state. It coincides with the binary Fe-19Mn alloy in the current research owing to the similar $\mathrm{SFE}^{21}$.

The plastic deformation mechanism of high manganese steels depends on the SFE of the $\gamma$-austenite phase ${ }^{22}$. Fe-Mn based damping alloys usually form deformation-induced $\varepsilon$ or $\alpha^{\prime}$ martensite instead of $\gamma$-austenite mechanical twins due to the extremely low SFE. However, the SFE is increased in the $\mathrm{Fe}-19 \mathrm{Mn}-8 \mathrm{Cr}-1 \mathrm{Co}-0.2 \mathrm{Si}$ alloy owing to the addition of $\mathrm{Cr}$. In this SFE level, the climbing and cross-slipping of dislocation are difficult, resulting in some mechanical twins are formed to coordinate plastic deformation because the plastic flow is seriously obstructed at large cold rolling deformation.

Figs. 7c and 7d present the bright-field image and the corresponding dark-field image obtained from $(01 \overline{1})_{\alpha^{\prime}}$ diffraction spot in the Fe-19Mn-8Cr-1Co-0.2Si alloy. The $\alpha$-martensite grain usually shows block-form or lath-form and is observed within a single $\varepsilon$-martensite plate or at the intersection of two $\varepsilon$-martensite bands, which is consistent with that observed by EBSD. In addition, owing to the simple displacive phase transformation mechanism of $\alpha^{\prime}$-martensite, hence the initial deformation-induced $\alpha^{\prime}$-martensite has a low dislocation density, as shown in Fig. $7 b$.

The stacking fault probability that means the number of stacking faults per unit volume in an alloy was calculated due to significance in damping capacity analyses. According to Warren's theory ${ }^{23}$, the deformation stacking fault probability $(\alpha)$ and the twinning stacking fault probability $(\beta)$ in $\varepsilon$-martensite can be calculated using peak-broad method on the basis of XRD patterns, however, the stacking fault probability of austenite cannot be obtained by this method for the diffraction peak may overlap between $\gamma$-austenite and $\varepsilon$-martensite. Hence, the peak-shift method ${ }^{17,24,25}$ is considered to calculate the stacking fault probability in the $\gamma$-austenite, although the result only includes the deformation stacking fault probability $(\alpha)$.

Table 2. Volume fractions of each phase after solution treatment (ST) and cold rolling (CR).

\begin{tabular}{lccc}
\hline Samples (wt.\%) & $\gamma$-austenite (\%) & $\varepsilon$-martensite (\%) & $\alpha^{\prime}$-martensite (\%) \\
\hline Fe-19Mn ST & 16.6 & 83.4 & 0 \\
Fe-19Mn CR 5\% & 11.0 & 89.0 & 0 \\
Fe-19Mn CR 8\% & 8.8 & 91.2 & 0 \\
Fe-19Mn CR 20\% & 2.9 & 91.8 & 5.3 \\
Fe-19Mn-8Cr-1Co-0.2Si ST & 27.2 & 72.8 & 0 \\
Fe-19Mn-8Cr-1Co-0.2Si CR 5\% & 22.1 & 77.9 & 0 \\
Fe-19Mn-8Cr-1Co-0.2Si CR 10\% & 10.8 & 85.2 & 4.0 \\
Fe-19Mn-8Cr-1Co-0.2Si CR 20\% & 6.4 & 81.6 & 12.0 \\
\hline
\end{tabular}




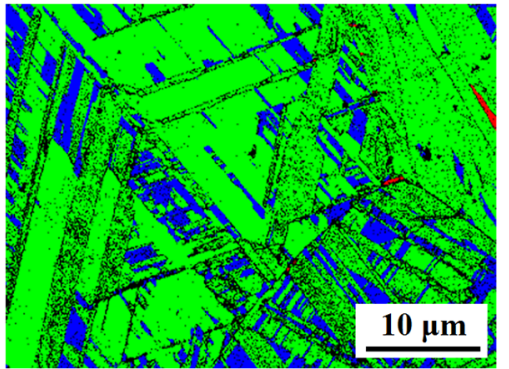

(a)

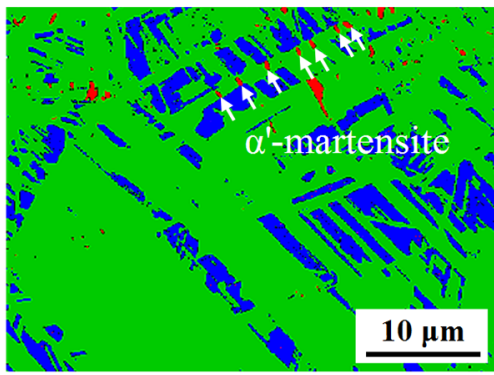

(d)

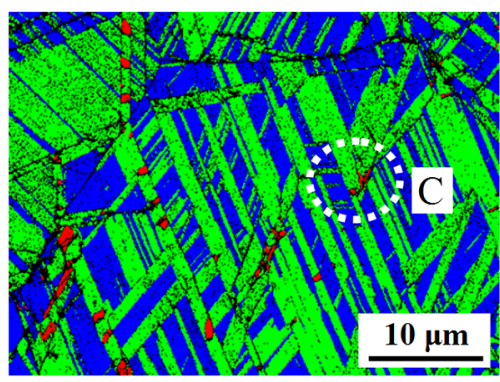

(g)

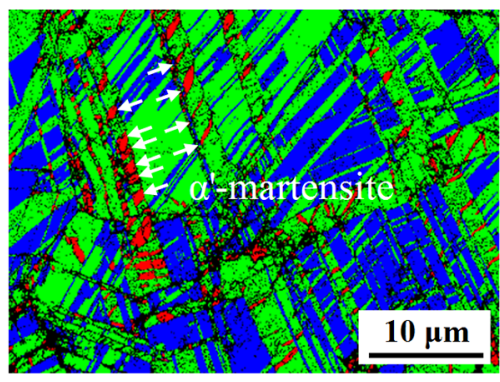

(j)

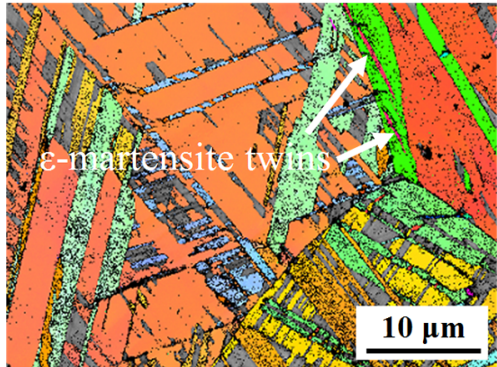

(b)

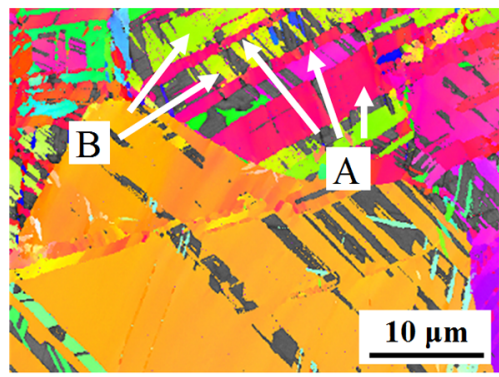

(e)

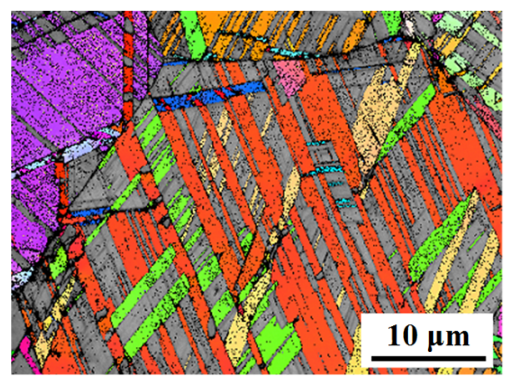

(h)

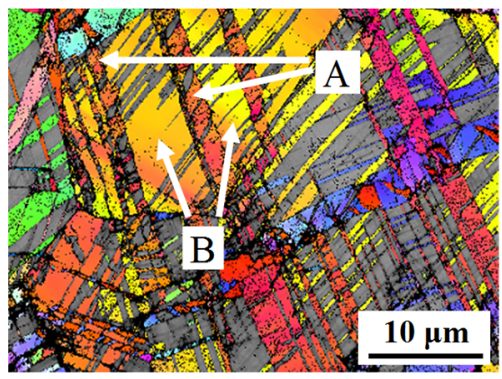

(k)

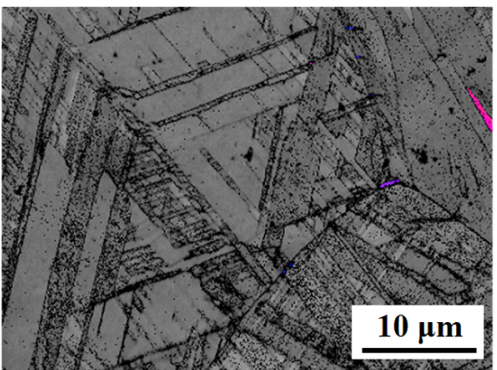

(c)

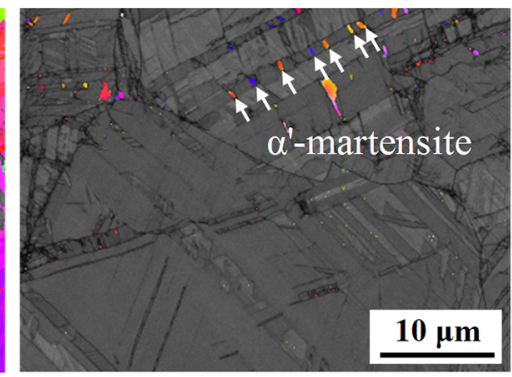

(f)

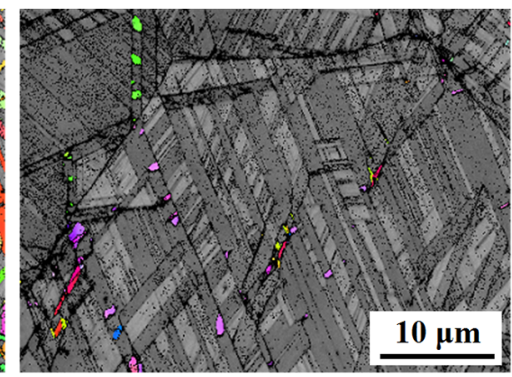

(i)

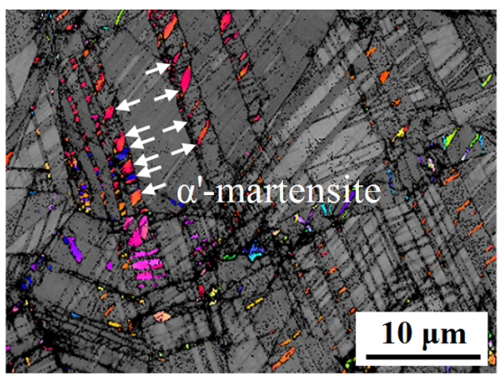

(1)

\section{$\gamma$-austenite}

$\varepsilon$-martensite

Figure 6. EBSD analysis on (a)-(f) the Fe-19Mn alloy and (g)-(1) the Fe-19Mn-8Cr-1Co-0.2Si alloy after cold rolling: (a)-(c) and (g)-(i) $5 \%$ deformation; (d)-(f) $8 \%$ deformation; (j)-(1) $10 \%$ deformation; (a), (d), (g) and (j) the phase maps; (b), (e), (h) and (k) the inverse pole figure maps of $\varepsilon$-martensite; (c), (f), (i) and (l) the inverse pole figure maps of $\alpha^{\prime}$-martensite. 


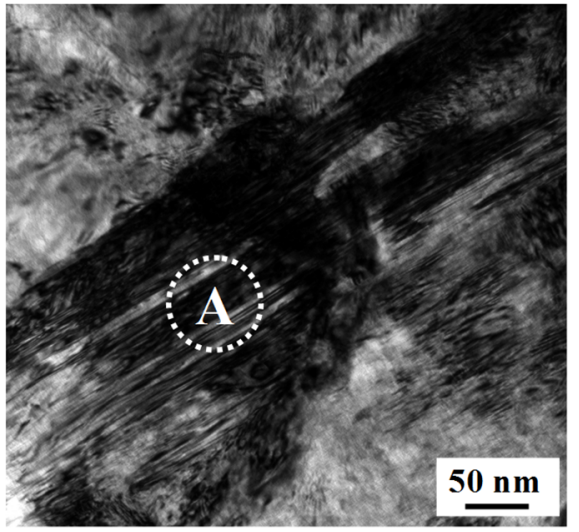

(a)

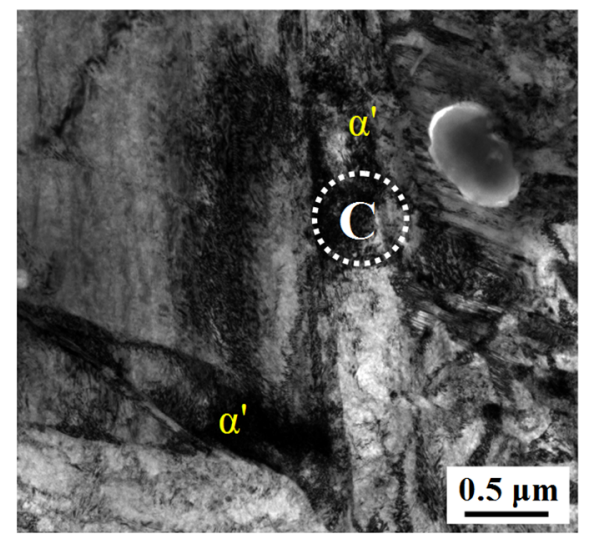

(c)

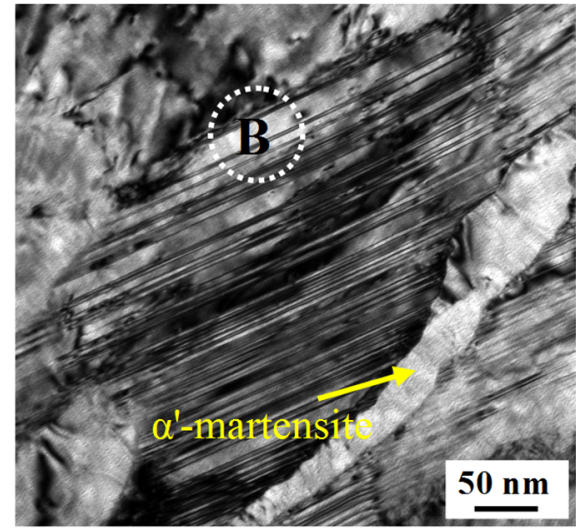

(b)

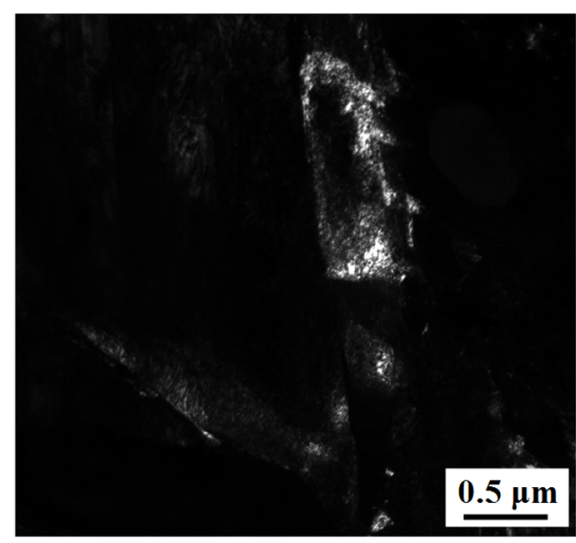

(d)

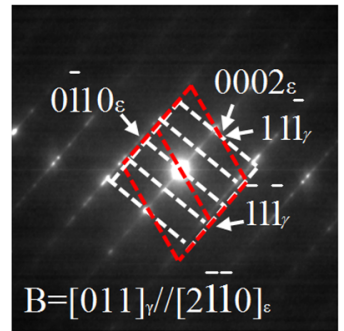

(e)

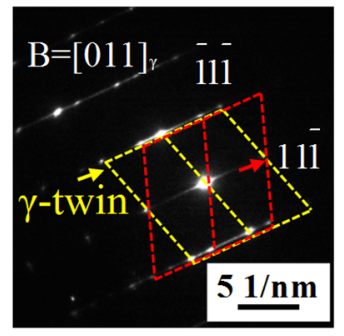

(f)

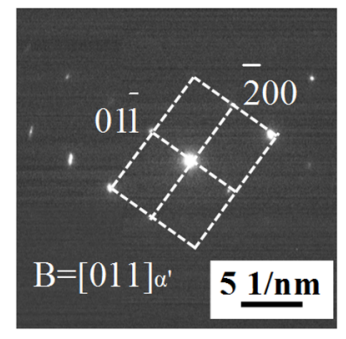

(g)

Figure 7. TEM micrographs of the Fe-19Mn-8Cr-1Co-0.2Si alloy after $20 \%$ cold rolling deformation: (a), (b) and (c) the bright-field image, showing high density dislocations; (d) the corresponding dark-field image obtained from (01-1) $\alpha^{\prime}$ diffraction spot; (e), (f) and (g) the SAEDP obtained from the region $\mathrm{A}, \mathrm{B}$ and $\mathrm{C}$ respectively.

According to the measured (100) and (101) diffraction peaks of $\varepsilon$-martensite, the stacking fault probability in $\varepsilon$-martensite $(3 \alpha+\beta)$ can be calculated as follows ${ }^{24}$.

$$
\begin{aligned}
& \frac{1}{D_{(e f f .100)}}=\frac{1}{D_{a v}} \\
& \frac{1}{D_{(e f f .101)}}=\frac{1}{D_{a v}}+\frac{d_{101}}{4 d_{002}^{2}}(3 \alpha+\beta)
\end{aligned}
$$

where $D_{a v}$ is the average crystallite size, $D_{e f f}$ is the effective crystallite size and $d$ is the interplanar distance of $(h k l)$. According to Scherrer's equation ${ }^{23}, D_{\text {eff }}$ can be established as follows:

$$
D_{(e f f . h k l)}=\frac{0.94 \lambda}{B_{1 / 2} \cos \theta_{h k l}}
$$

where $\lambda=1.54056 \AA, B_{1 / 2}$ is the peak width at half height and $\theta_{h k l}$ is the diffraction angle. Finally, $3 \alpha+\beta$ can be obtained by the following expression:

$3 \alpha+\beta=\frac{4 d_{002}^{2}}{0.94 \lambda d_{101}}\left(B_{(1 / 2.101)} \cos \theta_{101}-B_{(1 / 2.100)} \cos \theta_{100}\right)$

According to Ref.17 and Ref.25, the stacking fault probability in $\gamma$-austenite $(\alpha)$ can be calculated as follows:

$\Delta\left(2 \theta_{200}-2 \theta_{111}\right)=-\frac{90 \sqrt{3}}{\pi^{2}} \alpha\left(\frac{\tan \theta_{200}^{0}}{2}+\frac{\tan \theta_{111}^{0}}{4}\right)$

where $\theta_{h k l}$ is the diffraction angle in experimental alloys and $\theta^{\circ}{ }_{h k l}$ is the diffraction angle in no stacking faults alloys. According to Bragg's law, $\theta_{h k l}^{0}$ is: 


$$
2 \theta_{h k l}^{0}=2 \arcsin \left(\frac{\lambda \sqrt{h^{2}+k^{2}+l^{2}}}{2 a}\right)
$$

where $a$ is the lattice constant of $\gamma$-austenite.

Stacking fault probabilities of $\varepsilon$-martensite $(3 \alpha+\beta)$ and $\gamma$-austenite $(\alpha)$ are listed in table 3 . The $3 \alpha+\beta$ and $\alpha$ in the Fe-19Mn alloy consequently increase with increasing deformation owing to the increase of stacking faults generated by stress induction. In the $\mathrm{Fe}-19 \mathrm{Mn}-8 \mathrm{Cr}-1 \mathrm{Co}-0.2 \mathrm{Si}$ alloy, within $5 \%$ deformation, the $\alpha$ customarily increases with increasing deformation due to stress-induced stacking fault. However, beyond $5 \%$ deformation, the $\alpha$ descends with increasing deformation. The fact is considered that stacking faults can develop into $\varepsilon$-martensite, $\gamma$-austenite twins or dense stacking fault bands depending on the SFE and the treatment, meaning that the stacking faults can exist in other patterns such as twinning $\gamma$-austenite. Thus the $\alpha$ descends beyond $5 \%$ deformation because stacking faults are absorbed by $\gamma$-austenite twins (Fig. 7f).

Table 3. Stacking fault probabilities of $\gamma$-austenite $(\alpha)$ and $\varepsilon$-martensite $(3 \alpha+\beta)$ in the two alloys after solution treatment or cold rolling.

\begin{tabular}{lcc}
\hline Samples (wt.\%) & $\alpha\left(\times 10^{-2}\right)$ & $3 \alpha+\beta\left(\times 10^{-3}\right)$ \\
\hline Fe-19Mn ST & 1.4776 & 4.725 \\
Fe-19Mn CR 5\% & 1.8542 & 6.255 \\
Fe-19Mn CR 8\% & 2.3171 & 7.368 \\
Fe-19Mn CR 20\% & 2.4563 & 7.491 \\
Fe-19Mn-8Cr-1Co-0.2Si ST & 1.2278 & 3.451 \\
Fe-19Mn-8Cr-1Co-0.2Si CR 5\% & 1.3606 & 4.693 \\
Fe-19Mn-8Cr-1Co-0.2Si CR 10\% & 0.9542 & 5.158 \\
Fe-19Mn-8Cr-1Co-0.2Si CR 20\% & 0.5880 & 6.614 \\
\hline
\end{tabular}

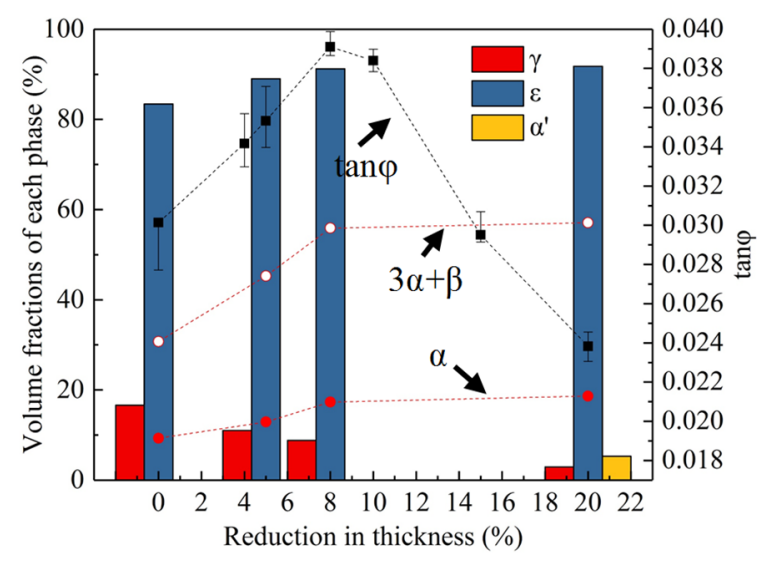

(a)

\subsection{Damping capacity}

Fig. 8 provides the damping capacity, volume fractions and stacking fault probabilities of the two alloys at different reduction in the thickness. It can be seen that the damping capacity in both alloys increases with increasing deformation, reaching a maximum, and then rapidly decreases. The solution-treated $\mathrm{Fe}-19 \mathrm{Mn}$ alloy has a significantly higher damping capacity than the solution-treated $\mathrm{Fe}-19 \mathrm{Mn}-8 \mathrm{Cr}$ $1 \mathrm{Co}-0.2 \mathrm{Si}$ alloy. It is considered with the fact that $\mathrm{Cr}$ is a typical austenite stabilizing element, the addition of $\mathrm{Cr}$ can hence increase the SFE of the Fe-19Mn-8Cr-1Co-0.2Si alloy and leads to a reduction of thermal-induced $\varepsilon$-martensite volume fraction. Moreover, it is consistent with Choi et al.'s result ${ }^{26}$ that the quenched Fe-17Mn alloy added strong austenite stabilizer $\mathrm{C}$ has a reduction in damping capacity owing to the decrease of damping sources associated with $\varepsilon$-martensite and stacking faults.

As shown in Fig. 8, the variation of damping capacity depends on two aspects. On one hand, the number of damping sources varies with increasing deformation owing to $\gamma \rightarrow \varepsilon$ $\rightarrow \alpha$ ' phase transformation and stress-induced stacking faults. The increase in $\varepsilon$-martensitic volume fraction, $3 \alpha+\beta$ and $\alpha$ leads to an increase of the damping source number, resulting in the enhancement of the damping capacity. However, beyond a critical deformation, the phase transformation from pre-existing austenite to deformation-induced $\varepsilon$-martensite and the generation of stress-induce stacking faults formed by partial dislocation slipping become difficult owing to the deformation-induced $\varepsilon \rightarrow \alpha^{\prime}$ phase transformation and dislocation block, respectively. The $\varepsilon$-martensitic volume fraction, $3 \alpha+\beta$ and $\alpha$ tend to saturate, therefore, it is hard to further increase the number of damping sources. Moreover,

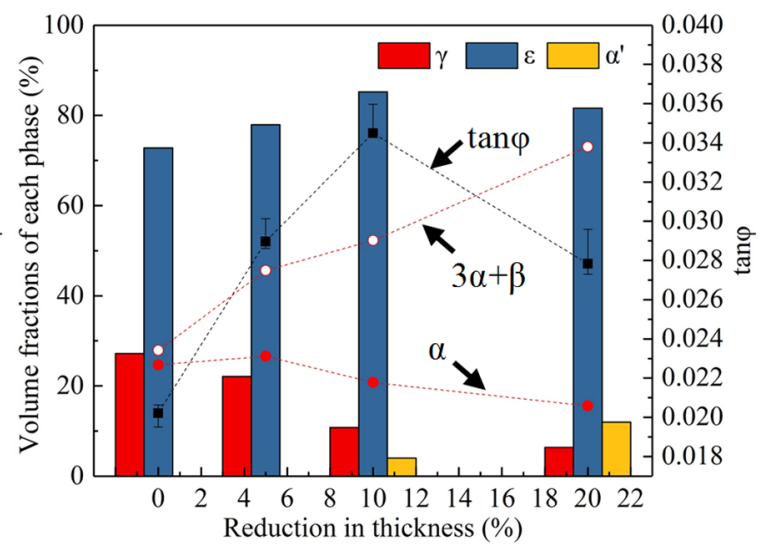

(b)

Figure 8. Damping capacities on the strain amplitude of $6 \times 10^{-4}$, Volume fractions of each phase and SF probabilities in the $\gamma$-austenite and $\varepsilon$-martensite: (a) the Fe-19Mn alloy and (b) the Fe-19Mn-8Cr-1Co-0.2Si alloy with different deformation. 
the deformation-induced $\alpha^{\prime}$-martensite is failure to provide damping sources and continuously increase in the fraction, therefore the number of damping sources is reduced and the damping capacity is deteriorated.

On the other hand, the mobility of damping sources declines with increasing deformation. Owing to a number of innumerable dislocations are generated during cold rolling, as shown in Figs. 7a, 7b and 7c, the movement of movable interfaces is impeded by dislocations and the damping capacity decreases rapidly at large deformation. For the $\mathrm{Fe}-19 \mathrm{Mn}-8 \mathrm{Cr}-1 \mathrm{Co}-0.2 \mathrm{Si}$ alloy, the $3 \alpha+\beta$ continuously increases with increasing deformation as shown in Fig. $8 \mathrm{~b}$, indicating that dislocations can normally slide at large plastic deformation. Given that the $\alpha^{\prime}$-martensite has richer slip system than $\varepsilon$-martensite due to the body-centered cubic crystal structure, hence the bcc phase can effectively promote the dislocation slipping and reduce the pinning effect of dislocations on damping sources. As a result, the deteriorated velocity of damping capacity is slower in the Fe-19Mn-8Cr-1Co-0.2Si alloy.

As shown in Fig. 8, the damping capacity maximum and the maximal increment in the Fe-19Mn and Fe-19Mn- $8 \mathrm{Cr}-$ $1 \mathrm{Co}-0.2 \mathrm{Si}$ alloy is $0.03910,0.00897,0.03450$ and 0.01492 , respectively. Obviously, the Fe-19Mn-8Cr-1Co-0.2Si alloy has a higher maximal increment. It is considered that the higher fraction of retained $\gamma$-austenite and faster $\gamma \rightarrow \varepsilon$ phase transformation rate lead to a higher volume fraction of $\varepsilon$-martensite, meaning that the alloy has a higher increment in the number of damping sources.

In addition, the $\gamma$-austenite mechanical twins are formed by displacive deformation behavior in the Fe-19Mn-8Cr$1 \mathrm{Co}-0.2 \mathrm{Si}$ alloy providing new damping sources, twinned boundaries. As in the $\mathrm{Mn}-\mathrm{Cu}$ damping alloys, these coherent or semi-coherent twinned boundaries can move and deplete mechanical energy under alternating stress ${ }^{27}$, however, the detail needs to be studied in later.

\section{Conclusions}

This work clarified the influence of cold rolling deformation on the microstructural evolution and damping capacities of the two Fe-Mn based damping alloys with significant difference in stacking fault energy. Based on this work, the following conclusions are derived:

(1) Before deformation, owing to the addition of $\mathrm{Cr}$, the SFE increased, the volume fraction of $\varepsilon$-martensite reduced and the damping capacity decreased in the Fe-19Mn-8Cr-1Co-0.2Si alloy.

(2) At lower deformation, the damping capacity of the two alloys enhanced owing to the increase of deformation-induced $\varepsilon$-martensite and stress-induced stacking faults. At the critical deformation, the transformation of $\gamma$-austenite to $\varepsilon$-martensite tended to saturate. With further deformation, the damping capacity decreased owing to the reduction in the number and mobility of damping sources.

(3) During deformation, the kinetics of the $\gamma$-austenite to $\varepsilon$-martensite phase transformation increased in the added $\mathrm{Cr}$ alloy and the phase transformation of $\varepsilon$-martensite to $\alpha$-martensite was hastened due to no twinned $\varepsilon$-martensite. Therefore, the damping capacity of the Fe-19Mn-8Cr-1Co-0.2Si alloy had a higher maximal increment and lower decline velocity.

(4) A new damping source, $\gamma$-austenite twinning boundaries, was provide in the $\mathrm{Fe}-19 \mathrm{Mn}-8 \mathrm{Cr}-1 \mathrm{Co}-$ $0.2 \mathrm{Si}$ alloy.

\section{Acknowledgements}

This work is supported by the National Key Research and Development Program of China (grant number 2016YFB0300303).

\section{References}

1. Huang SK, Wen YH, Li N, Teng J, Ding S, Xu YG. Application of damping mechanism model and stacking fault probability in Fe-Mn alloy. Materials Characterization. 2008;59(6):681-687.

2. Wen YH, Xiao HX, Peng HB, Li N, Raabe D. Relationship Between Damping Capacity and Variations of Vacancies Concentration and Segregation of Carbon Atom in an Fe-Mn Alloy. Metallurgical and Materials Transaction A. 2015;46(11):4828-4833.

3. Weng D, Liu S, He JC. Research and Industrialization Status of Mn-based Damping Alloys. Science \& Technology Review. 2014;32(3):77-83.

4. Baik SH. High damping Fe-Mn martensitic alloys for engineering applications. Nuclear Engineering and Design. 2000;198(3):241252.

5. Baik SH, Kim JC, Han DW, Kim TH, Back JH, Lee YK. FeMn martensitic alloys for control of noise and vibration in engineering applications. Materials Science and Engineering: A. 2006;438-440:1101-1105.

6. Lee YK, Jun JH, Choi CS. Damping Capacity in Fe-Mn Binary Alloys. ISIJ International. 1997;37(10):1023-1030.

7. Watanabe Y, Sato H, Nishino Y, Kim IS. Training effect on damping capacity in Fe-20 mass\% Mn binary alloy. Materials Science and Engineering: A. 2008;490(1-2):138-145.

8. Huang SK, Li N, Wen YH, Teng J, Xu YG, Ding S. Temperature dependence of the damping capacity in Fe-19.35Mn alloy. Journal of Alloys and Compounds. 2008;455(1-2):225-230.

9. Huang SK, Huang WR, Liu JH, Teng J, Li N, Wen YH. Internal friction mechanism of Fe-19Mn alloy at low and high strain amplitude. Materials Science and Engineering: A 2013;560:837840 .

10. Chen J, Zhang WN. Manganese dependence of microstructure and mechanical properties in Fe-Mn alloy. Materials Science and Technology. 2018;34(1):63-68. 
11. Granato A, Lücke K. Theory of Mechanical Damping Due to Dislocations. Journal of Applied Physics. 1956;27(6):583-593.

12. Jun JH, Choi CS. Effect of deformation on the damping capacity in an Fe-23 pet Mn alloy. Metallurgical and Materials Transaction A. 1999;30(3):667-670.

13. Huang SK, Zhou DC, Liu JH, Li CA, Li N, Wen YH. Effect of Pre-deformation on Damping Capacity of Fe-19Mn and Fe19Mn-1.5Si Alloys. Journal of Shanghai Jiaotong University. 2010;44(5):616-620.

14. Lee YK, Baik SH, Kim JC, Choi CS. Effects of amount of $\varepsilon$ martensite, carbon content and cold working on damping capacity of an $\mathrm{Fe}-17 \% \mathrm{Mn}$ martensitic alloy. Journal of Alloys and Compounds. 2003;355(1-2):10-16.

15. Wu B, Qian B, Wen Y. Effects of Cr on stacking-fault energy and damping of Fe-Mn. Materials Science and Technology. 2017;33(8):1019-1025.

16. Jun JH, Lee YK, Kim JM, Kim KT, Jung WJ. Influences of Si and Co Addition on Microstructure and Damping Capacity of Fe-Mn alloy. Key Engineering Materials. 2006;319:85-90.

17. Seol JB, Jung JE, Jang YW, Park CG. Influence of carbon content on the microstructure, martensitic transformation and mechanical properties in austenite/ $\varepsilon$-martensite dual-phase Fe-Mn-C steels. Acta Materialia. 2013;61(2):558-578.

18. Seol JB, Kim JG, Na SH, Park CG, Kim HS. Deformation rate controls atomic-scale dynamic strain aging and phase transformation in high Mn TRIP steels. Acta Materialia. 2017;131:187-196.

19. Yamanaka K, Mori M, Koizumi Y, Chiba A. Local strain evolution due to athermal $\gamma \rightarrow \varepsilon$ martensitic transformation in biomedical Co-Cr-Mo alloys. Journal of the Mechanical Behavior of Biomedical Materials. 2014;32:52-61.
20. Chen J, Zhang WN, Liu ZY, Wang GD. Microstructural evolution and deformation mechanism of a Fe-15Mn alloy investigated by electron back-scattered diffraction and transmission electron microscopy. Materials Science and Engineering: $A$. 2017;698:198-205

21. Lee YK. Effects of nitrogen on $\gamma \rightarrow \varepsilon$ martensitic transformation and damping capacity of $\mathrm{Fe}-16 \% \mathrm{Mn}-\mathrm{X} \% \mathrm{~N}$ alloys. Journal of Materials Science Letters. 2002;21(15):1149-1151.

22. Allain S, Chateau JP, Bouaziz O, Migot S, Guelton N. Correlations between the calculated stacking fault energy and the plasticity mechanisms in Fe-Mn-C alloys. Materials Science and Engineering: A. 2004;387-389:158-162.

23. Warren BE. X-ray Diffraction. Reading: Addison-Wesley; 1969. p. $85-90$.

24. Ramous E. Stacking-fault probability determination in hep metals and alloys. Zeitschrift für Metallkunde. 1974;65(7):515-518.

25. Guerrero LM, La Roca P, Malamud F, Baruj A, Sade M. Composition effects on the fcc-hcp martensitic transformation and on the magnetic ordering of the fcc structure in Fe-Mn- $\mathrm{Cr}$ alloys. Materials \& Design. 2017;116:127-135.

26. Choi WS, De Cooman BC. Effect of carbon on the damping capacity and mechanical properties of thermally trained Fe-Mn based high damping alloys. Materials Science and Engineering: A. 2017;700:641-648.

27. Zhong Y, Yin F, Sakaguchi T, Nagai K, Yang K. Dislocation structure evolution and characterization in the compression deformed Mn-Cu alloy. Acta Materialia. 2007;55(8):2747-2756. 